\title{
Residual Efficacy of Fungicides for Control of Dollar Spot on Creeping Bentgrass
}

\author{
Richard Latin, Department of Botany and Plant Pathology, Purdue University, West Lafayette, IN 47907-2054
}

\begin{abstract}
Latin, R. 2006. Residual efficacy of fungicides for control of dollar spot on creeping bentgrass. Plant Dis. 90:571-575.

The duration of effective concentrations of fungicides for control of dollar spot on creeping bentgrass fairways was investigated using a bioassay technique. In each of three runs of the experiment, fungicide treatments were applied once to turf in replicated field plots; then, the plots were sampled periodically over 3 weeks by removing turf plugs from the field. The sampled plugs were placed in incubation containers and inoculated with sections from a 4-day-old colony of Sclerotinia homoeocarpa growing on potato dextrose agar. After a 96-h incubation period, the extent of pathogen growth on the turf plugs was measured. Results described a precipitous decline in effective concentration for all fungicide treatments beginning 7 to 10 days after application. The fungicides were only marginally effective at 14 days after application, and none provided any disease suppression at 21 days after application. The efficacy half-life (EHL) associated with four of the fungicides (chlorothalonil, iprodione, propiconazole, and thiophanate methyl) was estimated with two models. EHL estimates ranged from 6.1 to 15.2 days depending on the fungicide and the model. This research contributes to our knowledge of the duration of effective fungicide concentrations on creeping bentgrass and can provide insight for scheduling fungicide sprays for golf course fairways.
\end{abstract}

Dollar spot, caused by Sclerotinia homoeocarpa F. T. Bennett, is a common disease of fine turf, especially creeping bentgrass. The pathogen infects turf foliage, blights individual leaf blades, and ruins aesthetic appearance and overall turf quality. On golf course greens and fairways, even mild outbreaks can be intolerable because the disease disturbs the uniformity of the turf surface and impairs playability $(13,18)$. Turf thinned as a result of dollar spot development is vulnerable to invasion by weed species, especially Poa annua (14). Golf course superintendents rely on repeated applications of fungicides for dollar spot control. Labels for fungicide products with various active ingredients specify application intervals from 7 to 28 days. In many cases, fungicides perform well and suppress or prevent serious outbreaks before the next scheduled spray is applied. However, there are numerous anecdotal reports from golf course superintendents where, despite application according to label specifications, the period of dollar spot suppression was much less than expected. Considering all of the factors that contribute to the depletion of fungicide from plant surfaces, including re-

Corresponding author: R. Latin

E-mail: rlatin@purdue.edu

Purdue University Agricultural Research Programs Journal Series Article No. 2005-17625.

Accepted for publication 29 November 2005.

DOI: 10.1094/PD-90-0571

(C) 2006 The American Phytopathological Society moval of deposit by rain or irrigation, photodegradation, volatilization, microbial degradation, and mowing and removal of clippings, the expectation that adequate fungicide protection will remain until the next scheduled application may not be reasonable, especially during extended periods when environmental conditions favor disease development $(6,8,12,17)$. Several reports $(4,5,7,11)$ explored the loss of fungicide from turf and turf soils, but none address the consequences in terms of residual efficacy against specific diseases. This research represents an investigation into the question of fungicide performance against dollar spot on creeping bentgrass fairways, and focuses on the length of time that effective concentrations remain within the turf. The objective was to describe and quantify the residual efficacy of fungicides applied for dollar spot control on golf course fairways. The approach involved a bioassay method, using S. homoeocarpa as the test fungus, to estimate the duration of fungicide effectiveness.

\section{MATERIALS AND METHODS}

The experiment was conducted three times, in summer 2003, fall 2003, and spring 2004. Experimental plots for each run were located at a different site on the same sward of creeping bentgrass (cv. L93) at the Daniel Turfgrass Research and Diagnostic Center on the campus of Purdue University in West Lafayette, IN. Fertilization, irrigation, and other maintenance operations were done according to standard practices for creeping bentgrass fairways. The turf was mowed at a cutting height of $1.3 \mathrm{~cm}$ three mornings per week
(Monday, Wednesday, and Friday). Clippings were removed with each mowing.

Fungicides commonly selected for dollar spot control by golf course superintendents were used in this research. They included chlorothalonil (Daconil Ultrex 82.5 WDG; Syngenta Crop Protection, Greensboro, NC) at $8.056 \mathrm{~kg}$ a.i. ha ${ }^{-1}$, iprodione (Chipco 26 GT 2SC; Bayer Environmental Science, Raleigh, NC) at $3.052 \mathrm{~kg}$ a.i. $\mathrm{ha}^{-1}$, mancozeb (Fore 80 WDG; Dow Agroscience, Indianapolis, IN) at $14.648 \mathrm{~kg}$ a.i. $\mathrm{ha}^{-1}$, propiconazole (Banner MAXX 1.3 MEC; Syngenta Crop Protection) at $0.496 \mathrm{~kg}$ a.i. $\mathrm{ha}^{-1}$, and thiophanate-methyl (Cleary 3336 4F; Cleary Chemical Company, Dayton, NJ) at 6.103 $\mathrm{kg}$ a.i. $\mathrm{ha}^{-1}$. The fungicides represent major classifications of turf fungicides based on topical mode of action. Chlorothalonil is a contact fungicide, iprodione is a localized penetrant, and propiconazole and thiophanate-methyl are acropetal penetrants (2).

For each run of the experiment, fungicide treatments were applied once to plots randomized within four replications. An unsprayed treatment was included in each replication. The plots measured 1 by $2 \mathrm{~m}$ and were separated by $0.5 \mathrm{~m}$ of unsprayed turf. Alleyways (2 m wide) separated the replications. Fungicides were applied with a custom-built boom sprayer. Three nozzles (Tee-Jet 8004 EVS, flat fan) were mounted approximately $30 \mathrm{~cm}$ apart on the boom and were positioned $30 \mathrm{~cm}$ above ground level. The sprayer was calibrated to deliver 18.7 liters $\mathrm{ha}^{-1}$ at a nozzle pressure of $2.8 \mathrm{~kg} \mathrm{~cm}^{-2}$. Treatment application dates for the three experiments were 6 August 2003 (summer 2003), 13 September 2003 (fall 2003), and 18 May 2004 (spring 2004). Three days prior to the application of treatments, the entire sward was treated with azoxystrobin (Heritage 50WG; Syngenta Crop Protection) at a rate of $0.61 \mathrm{~kg}$ a.i. $\mathrm{ha}^{-1}$ to suppress the growth of Rhizoctonia solani and other fungal contaminants that could interfere with $S$. homoeocarpa development during incubation of turf samples.

Turf was sampled periodically by removing small $(5 \mathrm{~cm}$ in diameter and $5 \mathrm{~cm}$ in depth) plugs from treated and untreated plots beginning with the day that fungicide was applied (day $=0$ ). Samples were collected during the early afternoon hours (when dew was not present) on days 0,3 , $7,10,14,17$, and 21 following fungicide application. Samples were collected from an area approximately $0.5 \mathrm{~m}$ wide and $1 \mathrm{~m}$ long in the center of each plot. Four replicate plugs from each treatment were 
placed in plastic containers on a laboratory bench and inoculated with a 3-mmdiameter section of a 4-day-old culture of $S$. homoeocarpa growing on potato dextrose agar. The isolate of $S$. homoeocarpa used for inoculations in all three runs of the experiment originally was obtained from symptomatic plants at the experimental site in June 2001, prior to the application of any fungicides to the turf. The isolate was identified as \#1169 and is sensitive to all fungicides addressed in this research. Approximately $100 \mathrm{ml}$ of water was added to the bottom of each inoculation container. Containers with inoculated plugs of creeping bentgrass were sealed in clear plastic bags and incubated at $20^{\circ} \mathrm{C}$ for $96 \mathrm{~h}$. After the incubation period, the diameter of the fungal growth across the plugs was measured and recorded.

Two metrics were created from the measurements of fungal growth across the creeping bentgrass plugs. The first was a disease severity (DS) percentage, which represents the measured pathogen growth diameter divided by the diameter of the turf plug $(5.0 \mathrm{~cm})$ multiplied by 100 . For each sample date, arcsine square roottransformed DS values were subjected to analysis of variance and mean separation procedures (PROC ANOVA) of SAS (version 9.1; SAS Institute, Inc., Cary, NC). The second metric was a residual efficacy (RE) proportion, whereby $\mathrm{RE}=(1-\mathrm{DS}$ treated plugs/DS-untreated plugs). The RE proportions were fit to two models to describe the decline in effective residual activity over time. For both models, trend lines were forced through the origin because the maximum relative residual efficacy cannot be anything but $100 \%$, or a proportion of 1.0. A first order decay model (negative exponential), $y=\mathrm{a} e^{-\mathrm{rt}}$, where $y$ is the RE proportion, $a$ is the initial efficacy proportion, $r$ is the rate of decay over time $(t)$, and $e$ is the natural logarithm base, traditionally is applied where pesticides are extracted from a variety of substrates, including soil and plant tissues $(5,10)$. In the linear form of the model, RE proportions were log transformed and regressed against time, forcing the line through the origin. The slope of the regression line $(r)$ describes the rate at which fungicide efficacy is reduced with increasing number of days from the application. The data also suggested that a second-order polynomial model might be appropriate. A simple polynomial (quadratic) model, $y=b_{1} x-b_{2} x^{2}$, where $y$ is the RE value, $x$ is time in days, and $b_{1}$ and $b_{2}$ are coefficients, also was applied to describe the dissipation of fungicide efficacy over time. The models were used to calculate an efficacy half-life (EHL) for each fungicide. The EHL was defined as the time in days after application for efficacy to be reduced to $50 \%$ and served as a basis for comparison of fungicides.

Further observations were made on inoculated, incubated turf plugs from the 7and 14-day samples from each experiment in order to verify that the bioassay was targeted against infection rather than extensive aerial growth of the fungus using the inoculum piece as substrate during the 96-h dew period. The plugs were removed from the incubation containers and placed in plastic pots (approximately 6 by $6 \mathrm{~cm}$ ) on a greenhouse bench where daily ambient temperature was maintained at 25 to $30^{\circ} \mathrm{C}$ and relative humidity ranged from 35 to $60 \%$. Plugs in pots were watered daily. After 2 weeks, the plugs were removed from the greenhouse bench and incubated in a saturated environment at $21^{\circ} \mathrm{C}$ for 72 $h$. The plugs then were examined for presence of mycelium consistent with that of $S$. homoeocarpa.

Field plots were evaluated visually for dollar spot severity (percentage of plot area with dollar spot symptoms) at weekly intervals using the Horsfall-Barratt disease assessment scale (1). DS data were used to calculate the area under the disease progress curve (AUDPC) for each treatment in each experiment (1).

\section{RESULTS}

The results of the Bartlett test for equality of variance associated with DS on turf plugs over the three experiments allowed for the pooling of the data (9). Also, there was no significant experiment by treatment interaction. Observations on turf plugs from sample days 7 and 14 that were removed to the greenhouse for two weeks showed that the bioassay was appropriate for assessment of infection by the dollar spot pathogen. In all cases where infection centers were measured, mycelial growth consistent with that of S. homoeocarpa was observed on symptomatic plants.

DS differed with fungicides and with sample dates (Table 1). Mancozeb was not effective against dollar spot, supporting local field observations and published reports $(3,15)$. The fact that pathogen growth was suppressed on mancozebtreated samples collected within hours of the fungicide application (day $=0)$ likely is due to high concentrations of the fungicide on the leaves immediately after application. Compared with the no-fungicide treatment, the four effective fungicides resulted in significant $(P=0.05)$ suppression of pathogen growth for 17 days (Table 1). Differences in DS among fungicide treatments were apparent after sample day 7. Less disease occurred on turf plugs treated with the acropetal penetrant fungicides (propiconazole and thiophanatemethyl) on sample days 10 and 14 (Table 1). Furthermore, DS on plugs from the chlorothalonil treatment was significantly less than that associated with iprodione on sample day 14 . By sample day 17 , differences were demonstrated among the four effective fungicide treatments (chlorothalonil, iprodione, propiconazole, and thiophanate-methyl), but with little practical significance because the least amount of disease (on turf plugs treated with propiconazole) was $76.7 \%$ (Table 1). By sample day 21 , DS on plugs treated with all fungicides did not differ from the untreated plugs.

Fitting the RE proportions to models that describe the decline in residual efficacy offered another method for comparing the fungicides. The linear form of the first-order decay model resulted in adequate descriptions of the loss of residual efficacy based on coefficients of determination (Fig. 1). This model apparently was a better fit for chlorothalonil $\left(R^{2}=0.70\right)$ and iprodione $\left(R^{2}=0.84\right)$ than the other fungicides (Fig. 1). The polynomial model resulted in more descriptive representations of the data for all fungicide treatments based on coefficients of determina-

Table 1. Disease severity expressed as the percentage of turf plug surfaces colonized by mycelium of Sclerotinia homoeocarpa for each fungicide at seven sampling dates

\begin{tabular}{|c|c|c|c|c|c|c|c|}
\hline \multirow[b]{2}{*}{ Fungicide $^{\mathrm{z}}$} & \multicolumn{7}{|c|}{ Days after fungicide application ${ }^{y}$} \\
\hline & $\mathbf{0}$ & 3 & 7 & 10 & 14 & 17 & 21 \\
\hline Propiconazole & $0.0 \mathrm{c}$ & $0.0 \mathrm{~b}$ & $5.0 \mathrm{~b}$ & $23.3 \mathrm{c}$ & $33.3 \mathrm{~d}$ & $76.7 \mathrm{c}$ & $92.7 \mathrm{a}$ \\
\hline Iprodione & $0.0 \mathrm{c}$ & $8.3 \mathrm{~b}$ & $18.3 \mathrm{~b}$ & $55.0 \mathrm{~b}$ & $76.7 \mathrm{~b}$ & $86.7 \mathrm{~b}$ & $95.0 \mathrm{a}$ \\
\hline Thiophanate-methyl & $0.0 \mathrm{c}$ & $1.7 \mathrm{~b}$ & $3.3 \mathrm{~b}$ & $26.7 \mathrm{c}$ & $32.0 \mathrm{~d}$ & $80.0 \mathrm{bc}$ & $95.0 \mathrm{a}$ \\
\hline Chlorothalonil & $0.0 \mathrm{c}$ & $1.7 \mathrm{~b}$ & $5.0 \mathrm{~b}$ & $53.3 \mathrm{~b}$ & $58.3 \mathrm{c}$ & $85.0 \mathrm{~b}$ & $98.3 \mathrm{a}$ \\
\hline Mancozeb & $15.0 \mathrm{~b}$ & $68.3 \mathrm{a}$ & $81.7 \mathrm{a}$ & $91.7 \mathrm{a}$ & $88.3 \mathrm{ab}$ & $98.3 \mathrm{a}$ & $100.0 \mathrm{a}$ \\
\hline No fungicide & $83.3 \mathrm{a}$ & $80.0 \mathrm{a}$ & $88.3 \mathrm{a}$ & $96.7 \mathrm{a}$ & $95.0 \mathrm{a}$ & $100.0 \mathrm{a}$ & $100.0 \mathrm{a}$ \\
\hline
\end{tabular}

\footnotetext{
y Values within columns followed by the same letter are not significantly different at $P=0.05$, Fischer's least significant difference test.
}

${ }^{\mathrm{z}}$ Fungicide products and application rates are as follows: Banner MAXX 1.3 MEC at $0.496 \mathrm{~kg}^{2}$.i. ha ${ }^{-1}$ (propiconazole), Chipco $26 \mathrm{GT} 2 \mathrm{SC}$ at $3.052 \mathrm{~kg}$ a.i. $\mathrm{ha}^{-1}$ (iprodione), Cleary $33364 \mathrm{~F}$ at $6.103 \mathrm{~kg}^{-1}$. ha ${ }^{-1}$ (thiophanate-methyl), Daconil Ultrex $82.5 \mathrm{WDG}^{-1} 8.056 \mathrm{~kg}$ a.i. ha ${ }^{-1}$ (chlorothalonil), and Fore 80 WDG at $14.648 \mathrm{~kg}$ a.i. ha ${ }^{-1}$ (mancozeb). 
tion that ranged from $R^{2}=0.89$ to 0.93 (Fig. 2).

The equations were used to estimate half-life values based on efficacy. According to estimates from the first-order decay model, the EHL for the four fungicides ranged from 6.1 to 9.5 days (Table 2). Based on the polynomial, EHL values ranged from 10.6 to 15.2 days (Table 2). Significant $(P=0.05)$ differences were observed among fungicides for both loss models. The ranking of the fungicides remained similar over both models in that propiconazole and thiophanate-methyl resulted in consistently greater EHL values. For iprodione and chlorothalonil, EHL estimates were statistically $(P=0.05)$ lower in some cases, and numerically lower in all cases, suggesting reduced levels of residual efficacy when compared with the acropetal penetrant fungicides (Table 2).

Dollar spot progress in the treatment field plots was monitored during each of the three experiments. Cool, dry weather during the fall 2003 experiment precluded disease development in all of the plots treated with effective fungicides. Dollar spot symptom expression was very light in unsprayed and mancozeb-treated plots. Consequently, there are no disease progress data for that experiment. Mild dollar spot development occurred during the summer 2003 experiment. Disease progress curves illustrate differences in dollar spot epidemics associated with each of the treatments (Fig. 3A). AUDPC values for propiconazole (12.0) and thiophanatemethyl (10.1) were not statistically different (Table 3). Iprodione and chlorothalonil treatments resulted in significantly more disease, with AUDPC values of 36.9 and 61.2, respectively (Table 3 ). Dollar spot development was more severe in the untreated plots during the spring 2004 experiment (Fig. 3B). However, acceptable levels of control were provided by iprodione, propiconazole, and thiophanatemethyl. Those treatments resulted in AUDPC values of 37.1, 26.7, and 24.7, respectively, and were not statistically different from one another (Table 3). The chlorothalonil treatment resulted in an epidemic with a significantly greater AUDPC value of 103.2 (Table 3).

\section{DISCUSSION}

The bioassay method demonstrated differences in residual efficacy of fungicides used for dollar spot control and contributed to a more quantitative understanding of the limitations of fungicides applied to creeping bentgrass fairways. The reduction of fungicide activity after 7 days is supported by results of investigations into the environmental fate of pesticides. Frederick et al. (5) observed rapid degradation of vinclozolin residues from creeping bentgrass clippings sampled 3, 7, and 14 days after a fungicide application. In a previous labora- tory simulation, they observed that the limit of vinclozolin detection in grass clippings was 21 days (4). Hsiang and Liu reported a 2.5-week half-life for methyl benzimidazole-2-ylcarbamate (MBC) in thatch, determined by bioassay (7). Also, Schumann et al. (11) reported a rapid de-
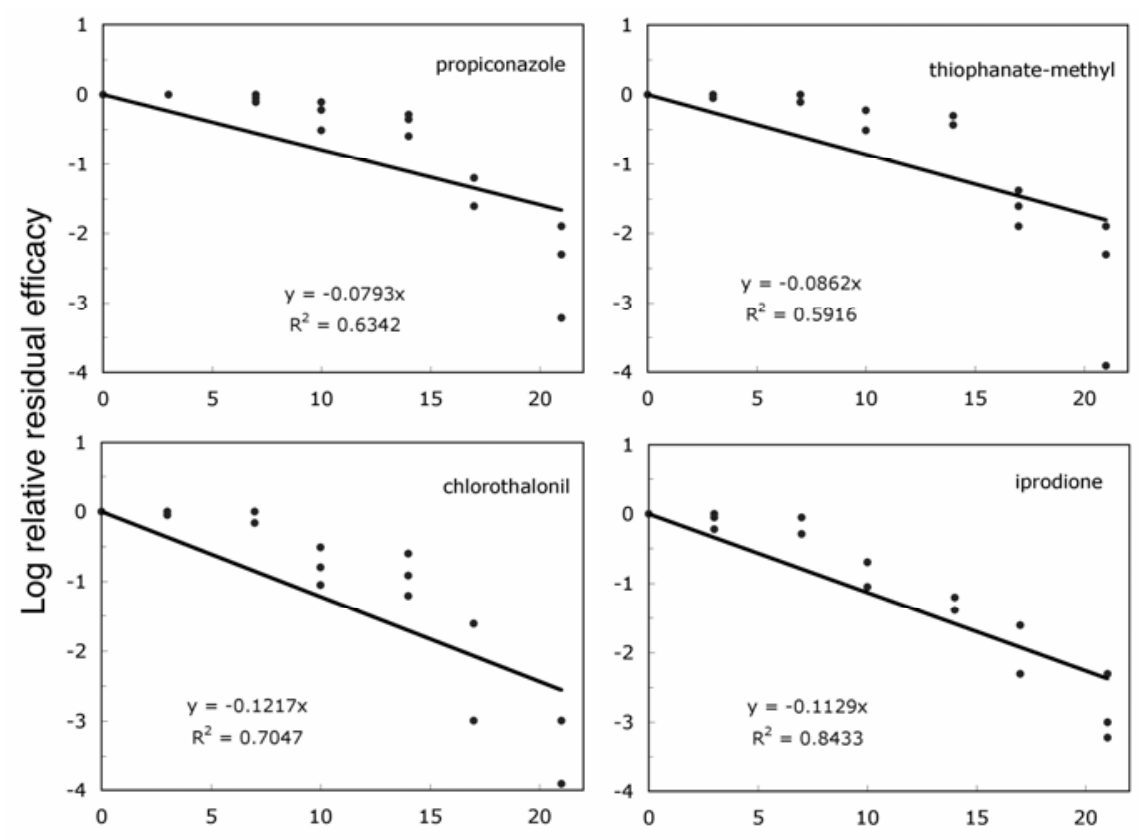

Days after fungicide application

Fig. 1. Log-transformed residual efficacy (RE) proportions for four fungicides (propiconazole, thiophanate-methyl, chlorothalonil, and iprodione) were regressed against time to describe the decline in residual efficacy.
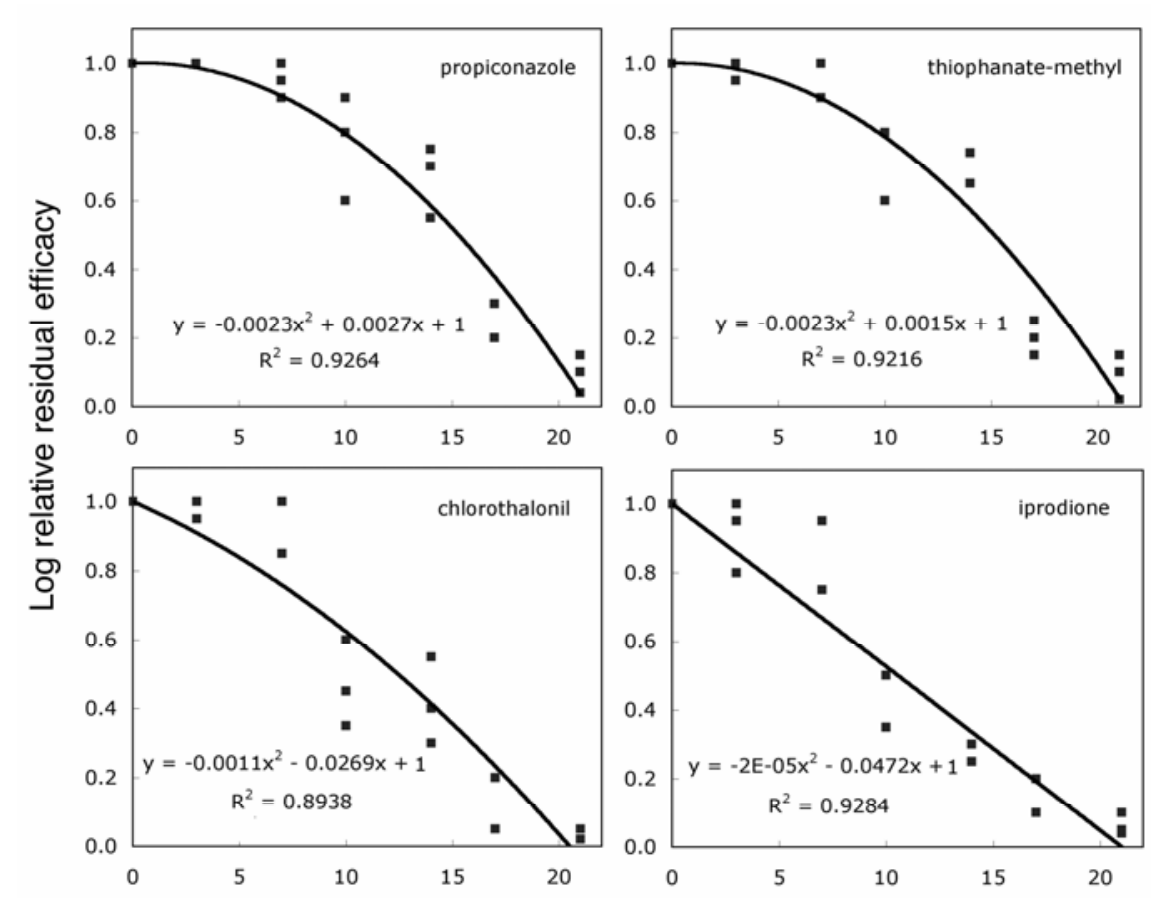

Days after fungicide application

Fig. 2. Residual efficacy (RE) proportions for four fungicides (propiconazole, thiophanate-methyl, chlorothalonil, and iprodione) were fit to a second-order polynomial model to describe the decline in residual efficacy over time.

cline in detectable residues of demethylation inhibitor (DMI) fungicides, including bluegrass. Although the reports did not specifically address chemical control of dollar spot, and involved only related fungicide compounds (except in one case),

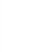


Table 2. Efficacy half-life (EHL) estimates for four fungicides based on two models that describe depletion of fungicide activity

\begin{tabular}{lcc}
\hline & \multicolumn{2}{c}{ EHL (days) } \\
\cline { 2 - 3 } Fungicide $^{\mathbf{z}}$ & First-order decay model & Polynomial model $^{-}$ \\
\hline Propiconazole & $9.5 \mathrm{a}$ & $15.2 \mathrm{a}$ \\
Iprodione & $6.4 \mathrm{bc}$ & $10.6 \mathrm{~b}$ \\
Thiophanate-methyl & $8.7 \mathrm{ab}$ & $15.1 \mathrm{a}$ \\
Chlorothalonil & $6.1 \mathrm{c}$ & $12.3 \mathrm{ab}$ \\
\hline
\end{tabular}

y Values within columns followed by the same letter are not significantly different at $P=0.05$ according to Fischer's least significant difference test.

${ }^{\mathrm{z}}$ Fungicide products and application rates are as follows: Banner MAXX $1.3 \mathrm{MEC}$ at $0.496 \mathrm{~kg}$ a.i. ha ${ }^{-1}$ (propiconazole), Chipco $26 \mathrm{GT} 2 \mathrm{SC}$ at $3.052 \mathrm{~kg}$ a.i. ha ${ }^{-1}$ (iprodione), Cleary $3336 \mathrm{4F}$ at $6.103 \mathrm{~kg}$ a.i. $\mathrm{ha}^{-1}$ (thiophanate-methyl), and Daconil Ultrex $82.5 \mathrm{WDG}$ at $8.056 \mathrm{~kg}$ a.i. $\mathrm{ha}^{-1}$ (chlorothalonil).

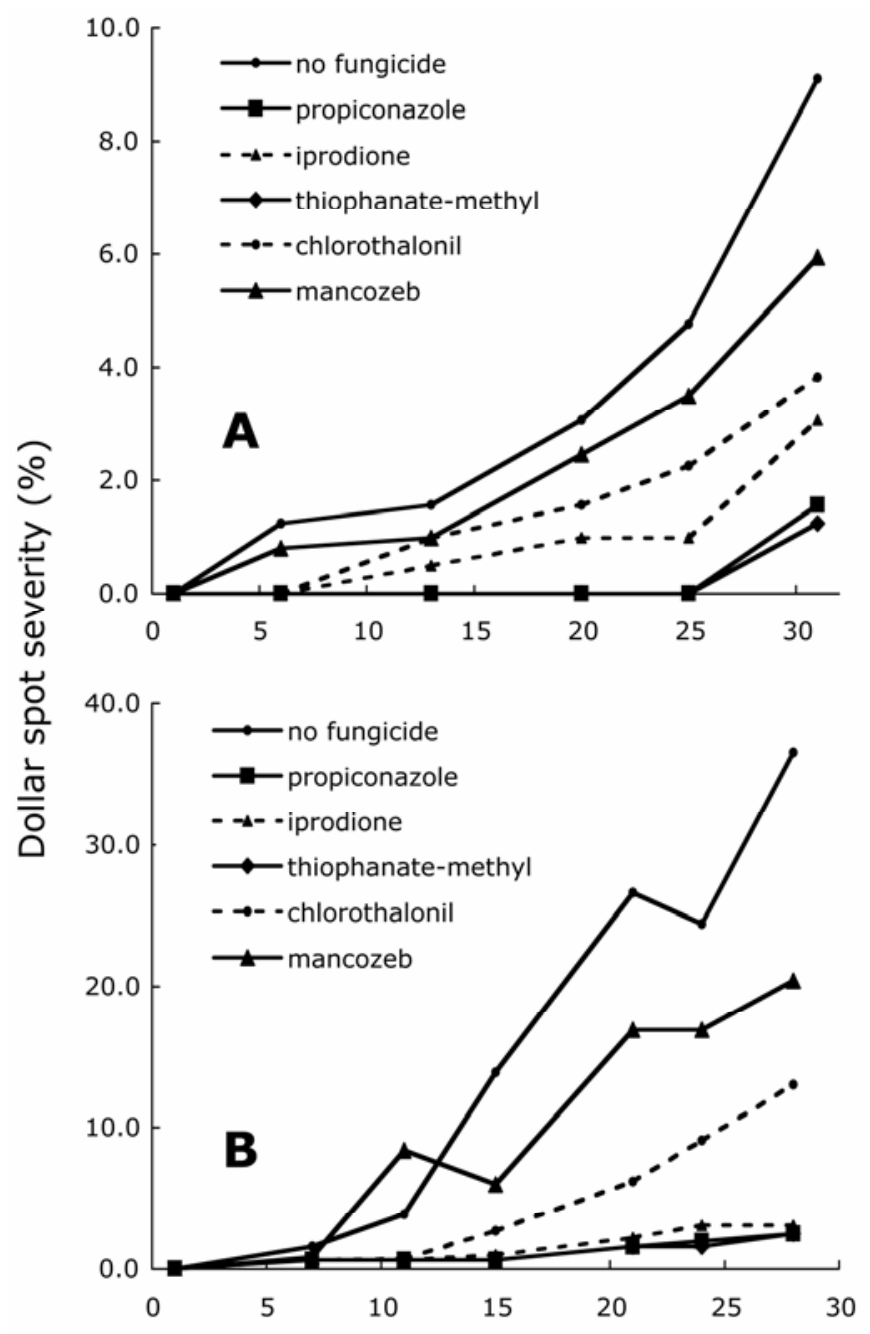

Days after fungicide application

Fig. 3. Disease progress curves illustrating field performance of fungicide treatments during A, summer 2003 and B, spring 2004. Each point on each line represents the mean of four replications. Fungicide products and application rates are as follows: Banner MAXX $1.3 \mathrm{MEC}$ at $0.496 \mathrm{~kg}$ a.i. ha ${ }^{-1}$ (propiconazole), Chipco $26 \mathrm{GT} 2 \mathrm{SC}$ at $3.052 \mathrm{~kg}$ a.i. ha-1 (iprodione), Cleary $33364 \mathrm{~F}$ at $6.103 \mathrm{~kg}$ a.i. $\mathrm{ha}^{-1}$ (thiophanate-methyl), Daconil Ultrex $82.5 \mathrm{WDG}$ at $8.056 \mathrm{~kg}^{2}$ a.i. ha ${ }^{-1}$ (chlorothalonil), and Fore 80 WDG at $14.648 \mathrm{~kg}$ a.i. $\mathrm{ha}^{-1}$ (mancozeb).

they all demonstrated a precipitous decline of recoverable or detectable fungicide residues from the turf canopy over time.

For each run of the experiment, the environmental conditions for inoculation and incubation of sampled turf plugs were the same. However, field experiments were conducted under different environmental pated and supports instructions that appear on fungicide labels. For example, using $1 \% \mathrm{DS}$ as a threshold, the contact fungicide (chlorothalonil) suppressed disease for about 14 days; the acropetal penetrants (propiconazole and thiophanate methyl) limited symptom expression to less than $1 \%$ for nearly 28 days, and the localized penetrant (iprodione) was somewhere in between.

Based on calculations with both models that describe the decline in residual efficacy over time, the EHL values were significantly greater for the acropetal penetrant fungicides (Table 2). However, the difference was a few days (approximately 3 days for the first-order decay model and 3 to 5 days for the polynomial), presenting a challenge to reconcile the observed minor difference in EHL with the doubling of the duration of control (from 14 to 28 days) as evidenced by disease progress in 2003 and 2004 (Fig. 3). Furthermore, the EHL values associated with the localized penetrant (iprodione) were similar to those of the contact fungicide (chlorothalonil), but iprodione resulted in significantly greater control in the field. Although there is no direct evidence, the likely explanation is that the chemotherapeutic properties of penetrant fungicides suppress existing infections, effectively reducing the inoculum in the field and the severity of disease over time (16). Both models describe the loss in fungicide efficacy over time, but which model more accurately represents loss in efficacy remains unclear. There is precedent for use of the decay model to describe the exponential loss of fungicide residues from plant foliage $(4,10)$; therefore, it seemed reasonable to use it to illustrate the loss of efficacy in quantitative terms. However, it may not be appropriate to use a single model to describe residual efficacy of fungicides with different modes of topical activity. Based on the appearance of the scatter plots and the coefficients of determination (Figs. 1 and 2), it appears that the first-order decay model best describes loss of efficacy for the contact and local penetrant fungicides, whereas the polynomial provides a more accurate description of the acropetal penetrant fungicides. Because there is some justification for each, both models are offered as a means for comparing loss of efficacy among fungicides over time.

The objective of this research was to quantify the decline in fungicide efficacy over time in an effort to understand why effective fungicides do not always perform up to expectations. Laboratory analytical methods detect and measure residues but do not address fungicide efficacy. Fungicide field trials provide assessments of product performance but are inadequate in expressing the loss of efficacy between applications. This simple bioassay method bridges laboratory research and field trials and achieves the 
Table 3. Area under the disease progress curve (AUDPC) calculations for dollar spot epidemics that occurred in experimental field plots during summer 2003 and spring 2004

\begin{tabular}{lcc}
\hline & \multicolumn{2}{c}{ AUDPCz } \\
\cline { 2 - 3 } Fungicide, formulated product, and application rate & Summer 2003 & Spring 2004 \\
\hline Propiconazole (Banner MAXX 1.3 MEC at 0.496 kg a.i. ha ${ }^{-1}$ ) & $12.0 \mathrm{e}$ & $26.7 \mathrm{~d}$ \\
Iprodione (Chipco 26 GT 2SC at 3.052 kg a.i. ha . $^{-1}$ & $36.9 \mathrm{~d}$ & $37.1 \mathrm{~d}$ \\
Thiophanate-methyl (Cleary 3336 4F at 6.103 kg a.i. ha $\mathrm{ha}^{-1}$ ) & $10.1 \mathrm{e}$ & $24.7 \mathrm{~d}$ \\
Chlorothalonil (Daconil Ultrex 82.5 WDG at 8.056 kg a.i. ha-1) & $61.2 \mathrm{c}$ & $103.2 \mathrm{c}$ \\
Mancozeb (Fore 80 WDG at 14.648 kg a.i. ha ${ }^{-1}$ ) & $105.7 \mathrm{~b}$ & $242.1 \mathrm{~b}$ \\
No fungicide & $149.3 \mathrm{a}$ & $418.8 \mathrm{a}$ \\
\hline
\end{tabular}

${ }^{\mathrm{z}}$ Disease progress curves are presented in Figure 3. Values within columns followed by the same letter are not significantly different at $P=0.05$ according to Fischer's least significant difference test.

objective of quantifying the decline of fungicide efficacy over time.

This investigation contributes to our knowledge regarding the residual efficacy of fungicides on creeping bentgrass fairways. Effective concentrations remain in the turf canopy for only about 1 to 2 weeks. Beyond the effective half-life of the fungicide, disease will develop more rapidly than the fungicide's capacity to suppress it, especially under favorable environmental conditions. Hence, outbreaks would tend to occur sooner than expected and another spray might be warranted before the expiration of the scheduled application interval. This scenario would help explain some anecdotal evidence where fungicide performance was inadequate despite the proper use of an effective product against a fungicide-sensitive isolate of the pathogen. This suggests a need for fundamental research on residual efficacy of fungicides under a variety of environmental regimes for better guidance in scheduling fungicide applications for dollar spot control on creeping bentgrass.

\section{LITERATURE CITED}

1. Campbell, C. L., and Madden, L. V. 1990. An Introduction to Plant Disease Epidemiology. John Wiley and Sons, Inc., New York.

2. Couch, H. B. 2000. The Turfgrass Disease Handbook. Kreiger Publishing Company, Malabar, FL.

3. Dernoeden, P. H., Kaminski, J. E., and Krouse, J. M. 2002. Dollar spot control with fungicides, nitrogen sources, and a wetting agent, 2001. Fungic. Nematicide Tests (online). Report 57:T06. DOI: 10.1094/ FN57. The American Phytopathological Society, St. Paul, MN.

4. Frederick, E. K., Bischoff, M., Throssell, C. S., and Turco, R. F. 1994. Degradation of chloroneb, triadimefon, and vinclozolin in soil, thatch, and grass clippings. Bull. Environ. Contam. Toxicol. 53:536-542.

5. Frederick, E. K., Throssell, C. S., Bischoff, M., and Turco, R. F. 1996. Fate of vinclozolin in creeping bentgrass turf under two application frequencies. Bull. Environ. Contam. Toxicol. 57:391-397.

6. Hewitt, H. G. 1998. Fungicides in Crop Protection. CAB International, New York.

7. Hsiang, T., and Liu, L. X. 1996. Estimating benzimidazole residues in thatch and turfgrass by bioassay. Pestic. Sci. 46:139-143.

8. Neely, D. 1970. Persistence of foliar protective fungicides. Phytopathology 60:1583-1586.
9. Neter, J., Wasserman, W., and Kutner, M.H 1985. Applied Linear Statistical Models. Second ed. Irwin Press, Homewood, IL.

10. Nokes, S. E., and Young, J. H. 1992. Predicting the persistence and efficacy of chlorothalonil on peanut leafspot. Trans. ASAE 35(5):1699. 1708

11. Schumann, G. L., Marshall Clark, J., Doherty, J. J., and Clarke, B. B. 2000. Application of DMI fungicides to turfgrass with three delivery systems. In: Fate and Management of Turfgrass Chemicals. J. M. Clark and M. P. Kenna, eds. American Chemical Society, Washington, D.C.

12. Sigler, W. V., Taylor, C. P., Throssell, C. S Bischoff, M., and Turco, R. F. 2000. Environmental fates of fungicides in the turfgrass environment: a minireview. In: Fate and Management of Turfgrass Chemicals. J. M. Clark and M. P. Kenna, eds. American Chemical Society, Washington, D.C

13. Smiley, R. W., Dernoeden, P. H., and Clarke, B. B. 2005. Compendium of Turfgrass Diseases, 3rd ed. American Phytopathological Society, St. Paul, MN.

14. Smith, J. D., Jackson, N., and Woolhouse, A.R. 1989. Fungal Diseases of Amenity Turf Grasses, 3rd ed. E. and F. N. Spon, New York.

15. Uddin, W., Soika, M. D., and Soika, E. L. 2002. Evaluation of fungicides for control of dollar spot on a putting green, 2001. Fungic Nematicide Tests (online). Report 57:T26. DOI: $10.1094 /$ FN57. The American Phytopathological Society, St. Paul, MN.

16. Vanderplank, J. E. 1963. Control of disease by fungicides. Pages 260-274 in: Plant Diseases: Epidemics and Control. Academic Press, New York.

17. Wain, R. L., and Carter, G. A. 1967. Uptake, translocation and transformation by higher plants. In: Fungicides: An Advanced Treatise. D. C. Torgeson, ed. Academic Press, New York.

18. Walsh, B., Ikeda, S. S., and Boland, G. J. 1999. Biology and management of dollar spot (Sclerotinia homoeocarpa); an important disease of turfgrass. HortScience 34:13-21 